Bài báo khoa học

\title{
Nghiên cứu ứng dụng chỉ số khô hạn $K$ đánh giá mức độ hạn hán trên địa bàn tỉnh Bình Thuận
}

\section{Nguyễn Hồng Trường1* ${ }^{*}$ Trần Văn Hưng1, Từ Thị Năm²}

${ }^{1}$ Đài Khí tượng Thủy văn khu vực Nam Trung Bộ; truongmeteo@gmail.com; tranhungdubao@gmail.com

2 Trường Đại học TNMT TP Hồ Chí Minh; ttnam@hcmunre.edu.vn

*Tác giả liên hệ: truongmeteo@gmail.com; Tel.: +84-905490246

Ban Biên tập nhận bài: 15/10/2021; Ngày phản biện xong: 6/12/2021; Ngày đăng bài: $25 / 2 / 2022$

Tóm tắt: Bình Thuận diễn biến hạn hán, thiếu nước ngày càng gia tăng, nguồn nước đang ngày càng khan hiếm. Để đảm bảo đủ nguồn nước phục vụ cho phát triển kinh tế - xã hội thì công tác quản lý, phòng chống hạn là vấn đề cần được quan tâm. Trong bài báo này ứng dụng chỉ số hạn $\mathrm{K}$ (chỉ số cán cân nguồn nước), đánh giá mức độ khô hạn, thiếu nước và xây dựng bản đồ hạn hán tại tỉnh Bình Thuận đã cho một cái nhìn tổng quan về hạn và khả năng xảy ra hạn và đây cũng là cơ sở để tham khảo trong thiết lập hệ thống đánh giá, giám sát và cảnh báo hạn hán, cho phép định hướng khai thác nguồn nước hợp lý.

Từ khóa: Chỉ số khô hạn (K); Tần suất hạn; Bình Thuận.

\section{Mở đầu}

Trong những năm gần đây hạn hán xảy ra nhiều nơi trên cả nước nói chung, tỉnh Bình Thuận nói riêng, gây ra nhiều thiệt hại, ảnh hưởng đến đời sống con người, môi trường sinh thái. Nhiều tổ chức quốc tế và nhiều quốc gia trên thế giới đã tiến hành nghiên cứu hạn hán với mục tiêu chung là góp phần dự báo, cảnh báo, khai thác nguồn tài nguyên nước hợp lý, hạn chế tác động của hạn hán đối với đời sống con người, sản xuất và môi trường sinh thái [1]. Hiện tượng hạn hán được xem là một trong số các hiện tượng khí hậu cực đoan, một loại thiên tai phổ biến ở trên thế giới nói chung và Việt Nam nói riêng. Việc nắm bắt các quy luật diễn biến khí hậu để quản lý, khai thác nguồn nước hợp lý, có ý nghĩa cấp thiết trong thời kỳ công nghiệp hóa, hiện đại hóa đất nước.

Ở nước ta, đã có nhiều công trình nghiên cứu ứng dụng các chỉ số hạn hán khác nhau phục vụ việc đánh giá hiện trạng, biến đổi, giám sát, cảnh báo và dự báo [2-3]. Sử dụng chỉ số khổ hạn $\mathrm{K}$ (tỷ số giữa phần chi và phần thu chủ yếu của cán cân nước) trong các nghiên cứu về hạn. [4-8] sử dụng chỉ số $\mathrm{K}, \mathrm{SPI}$, tỷ chuẩn lượng mưa (TC), thiếu hụt lượng mưa (D) và chỉ số phục hồi hạn hán (RDI) để đánh giá và xây dựng các bản đồ hạn hán và thiếu nước sinh hoạt trên khu vực Tây Nguyên và Nam Trung Bộ. [9-10] sử dụng chỉ số SPI đã được ứng dụng nghiên cứu đánh giá, giám sát, cảnh báo và dự báo hạn hán ở Việt Nam. [11] đã sử dụng chỉ số $\mathrm{K}_{\mathrm{hạn}}$ được tính toán từ kết quả mô phỏng dòng chảy từ mô hình SWAT xây dựng bản đồ phân vùng hạn hán lưu vực sông Ba....

Mỗi chỉ số hạn, hệ số khô hạn đều có ưu, nhược điểm khác nhau và mỗi khu vực thường phải nghiên cứu kĩ từng chỉ số hạn để áp dụng cho phù hợp với điều kiện khí hậu, diễn biến hạn thực tế đã xảy ra ở địa phương. Việc nghiên cứu đánh giá khô hạn tại tỉnh Bình Thuận có ý nghĩa hết sức quan trọng, là cơ sở để các nhà quản lý các sở, ngành có những quyết sách phù 
hợp để khai thác, sử dụng nguồn nước, bố trí mùa vụ, cơ cấu cây trồng hợp lý và đưa ra các biện pháp thích ứng với hạn hán, nhằm giảm thiểu rủi ro hạn hán từ cấp xã, huyện trên địa bàn tỉnh [12]; đặc biệt ở những vùng đất hoang hóa, khô cằn trở nên hữu dụng theo yêu cầu phát triển kinh tế - xã hội sát với thực tiễn tại địa phương [13].

\section{Phương pháp nghiên cứu}

\subsection{Giới thiệu khu vục nghiên cưu}

Bình Thuận là một tỉnh duyên hải Nam Trung Bộ, trong giới hạn tọa độ địa lý từ

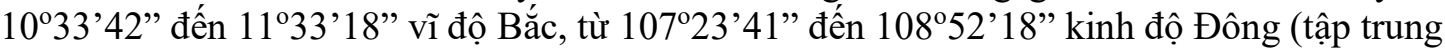
các huyện) (Hình 1).

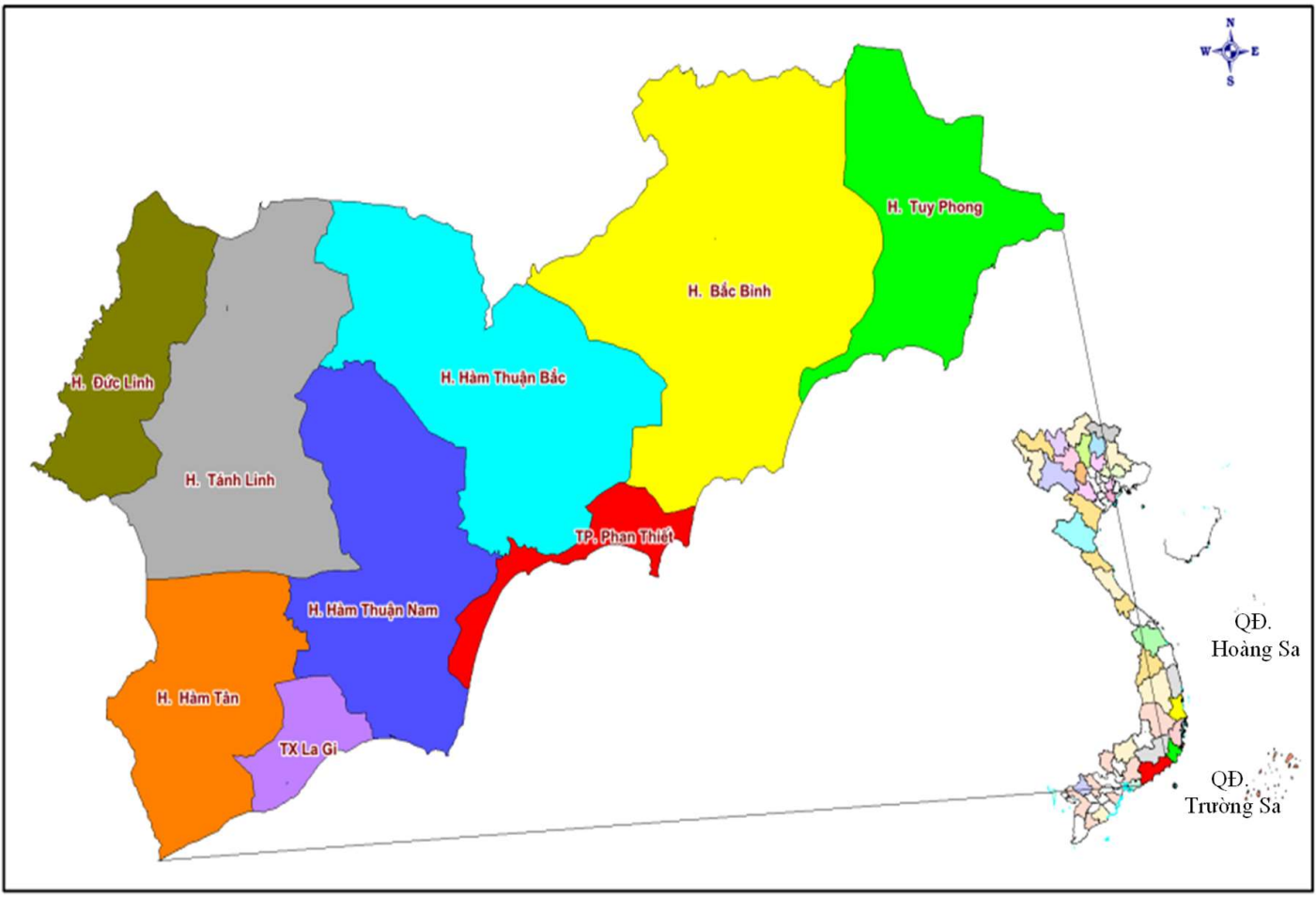

Hình 1. Bản đồ pham vi nghiên cứu.

Trong những năm gần đây, dưới tác động của biến đổi khí hậu [14-15] đã làm diễn biến thời tiết thủy văn ngày càng phức tạp, biểu hiện ở nhiệt độ có xu hướng tăng, lượng mưa và dòng chảy mùa cạn giảm mạnh càng làm nguy cơ suy thoái nguồn nước, tăng khả năng, mức độ thiếu nước, hạn hán ở khu vực Bình Thuận, điển hình như các năm 1998, 2004, 2005, 2010, 2013, 2014, 2015, 2016, 2019-2020.

\subsection{Cơ sở dĩ liệu}

Nghiên cứu đã sử dụng trên 12 trạm, trong đó 4 trạm khí tượng, 2 trạm thủy văn, 6 điểm đo khảo sát trong tỉnh (Hình 2). Đối với diện tích tỉnh Bình Thuận, số điểm, số trạm đo như vậy là tương đối phù hợp. Khoảng cách các trạm, điểm đo gần nhất là $8,3 \mathrm{~km}$ và xa nhất là 45 $\mathrm{km}$. Chuỗi số liệu tại các trạm khí tượng, thủy văn, điểm đo mưa nhân dân tỉnh Bình Thuận, chủ yếu bắt đầu có từ năm 1978 đến 2020, đã được phúc thẩm kiểm tra theo qui chuẩn của ngành khí tượng thủy văn, đảm bảo tính liên tục, đủ dài theo tính toán yêu cầu cho các đặc trưng khí hậu, thủy văn [16]. 
Bảng 1. Mạng lưới trạm tỉnh Bình Thuận [16].

\begin{tabular}{cllc}
\hline STT & \multicolumn{1}{c}{ Trạm } & \multicolumn{1}{c}{ Yếu tố đo } & Thời gian \\
\hline 1 & Phan Rí & Nhiệt độ, bốc hơi, mưa, ẩm, gió,.. & $1978-2020$ \\
2 & TV Sông Lũy & Mực nước, lưu lượng, mưa, nhiệt độ, bốc hơi... & $1978-2020$ \\
3 & Hồng Liêm & Nhiệt độ, bốc hơi, mưa, ẩm & Đo khảo sát \\
4 & Ma Lâm & Nhiệt độ, bốc hơi, mưa, ẩm & Đo khảo sát \\
5 & Phan Thiết & Nhiệt độ, bốc hơi, mưa, ẩm, gió,.. & $1978-2020$ \\
6 & Hàm Kiệm & Nhiệt độ, bốc hơi, mưa, ẩm & Đo khảo sát \\
7 & TV Tà Pao & Mực nước, lưu lượng, mưa, nhiệt độ, bốc hơi... & $1978-2020$ \\
8 & Ngã Ba 46 & Nhiệt độ, bốc hơi, mưa, ẩm & Đo khảo sát \\
9 & La Gi & Nhiệt độ, bốc hơi, mưa, ẩm, gió,... & $1978-2020$ \\
10 & Võ Xu & Nhiệt độ, bốc hơi, mưa, ẩm & Đo khảo sát \\
11 & La Ngâu & Nhiệt độ, bốc hơi, mưa, ẩm & Đo khảo sát \\
12 & Phú Quý & Mực nước biển, mưa, nhiệt độ, bốc hơi, ẩm ... & $1978-2020$ \\
\hline
\end{tabular}

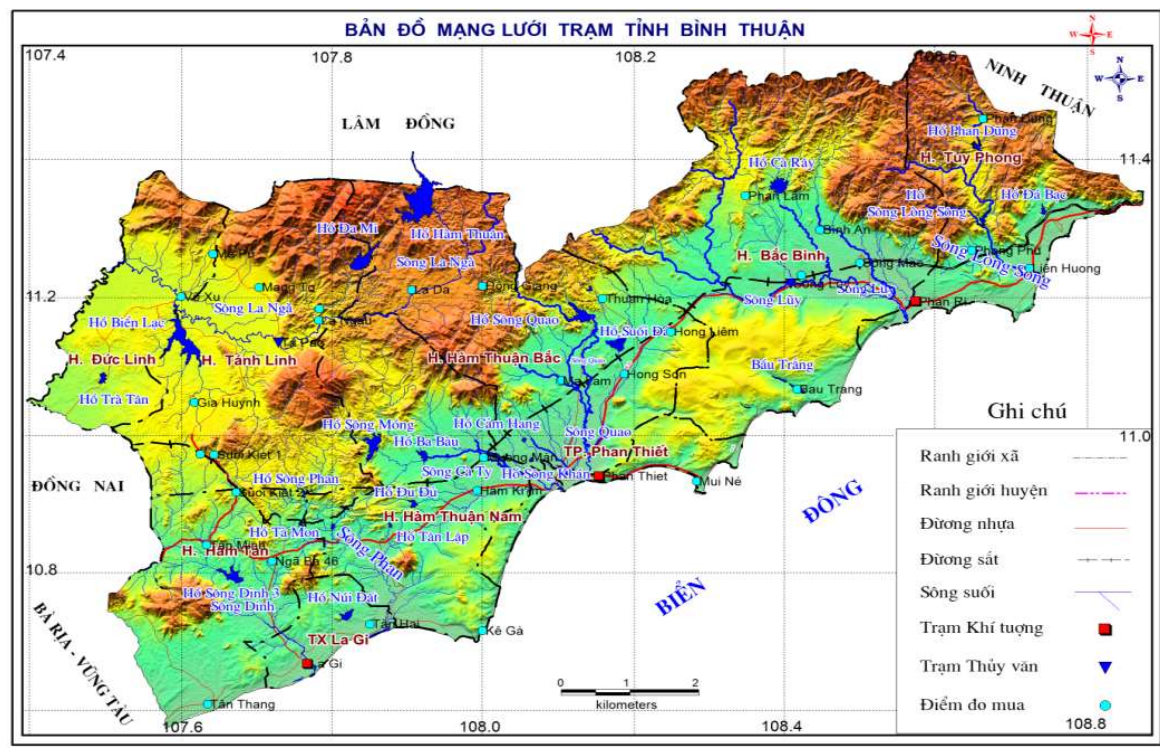

Hình 2. Bản đồ mạng lưới trạm, sông suối tỉnh Bình Thuận.

\subsection{Lựa chọn chỉ số hạn và xây dựng phương pháp phân vùng hạn phù hợp thực tế tại tỉnh} Bình Thuận

a) Định hướng lựa chọn chỉ tiêu xác định hạn khí tượng

Chỉ tiêu xác định hạn phải phản ánh được các đặc trưng cơ bản sau đây về tình hình hạn ở Bình Thuận [8]:

- Hạn phân bố theo mùa, tùy thuộc vào chế độ mưa.

- Hạn chủ yếu xảy ra trong mùa khô xong cũng có thể xảy ra trong một thời gian nào đó của mùa mưa.

- Hạn có thể xảy ra ở vùng này nhưng không xảy ra ở vùng khác, thận chí trên cùng một vùng hạn có thể xảy ra ở địa điểm này nhưng không thể xảy ra ở địa điểm khác.

- Mức độ hạn gắn liền với tần suất hạn, thời gian kéo dài của hạn và cường độ hạn hay mức thâm hụt về lượng mưa trong quá trình hạn. 
Qua quá trình tính toán, chọn lọc các chỉ tiêu khô hạn, tần suất xuất hiện khô hạn tại khu vực tỉnh Bình Thuận. Trong bài báo này tác giả đã lựa chọn chỉ số khô hạn $(\mathrm{K})$ [1] để nghiên cứu cho khu vực tỉnh Bình Thuận.

* Chỉ số khô hạn $\mathrm{K}$ : $\quad \mathrm{K} i=\frac{\mathrm{E} i}{\mathrm{R} i}$

Trong đó Ei là lượng bốc hơi Picche thời đoạn tính toán (sử dụng số liệu tháng, mùa, năm); Ri là lượng mưa thời đoạn tính toán (sử dụng số liệu tháng, mùa, năm).

Bảng 2. Ngưỡng các chỉ tiêu đánh gián khô hạn [1].

\begin{tabular}{cc}
\hline Hệ số $\mathbf{K}$ & Khoảng giá trị \\
\hline Ầm & $<1,0$ \\
Hơi khô & $1,0 \leq \mathrm{K} \leq 2,0$ \\
Khô hạn & $2,0<\mathrm{K}<4,0$ \\
Rất khô hạn & $\mathrm{K} \geq 4$ \\
\hline
\end{tabular}

* Công thức tính tần suất khô hạn

$$
\mathrm{Ph}(\%)=\frac{\mathrm{m}(\mathrm{H})}{\mathrm{n}(\mathrm{H})}
$$

Trong đó $\mathrm{Ph}$ là tần suất hạn cần tính (tháng, mùa, năm); $\mathrm{H}$ là sự kiện xảy ra hạn (tháng, mùa, năm); $\mathrm{m}(\mathrm{H})$ là số lần xảy ra khô hạn (tháng, mùa, năm); $\mathrm{n}(\mathrm{H})$ là số lần tính toán (tháng, mùa, năm).

b) Phương pháp phân vùng khô hạn

* Phương pháp phân vùng khô hạn tỉnh Bình Thuận: Dựa theo phương pháp nội suy không gian IDW (Inverse Distance Weight) Để xây dựng bản đồ phân vùng hạn chúng tôi đã dùng phương pháp nội suy không gian IDW. Phương pháp tính nội suy dựa theo khoảng cách đến các trạm lân cận có cùng điều kiện theo công thức sau:

$$
P=\frac{\sum\left(\frac{\mathrm{Pi}}{\mathrm{r}^{\mathrm{b}}}\right) \mathrm{i}}{\sum\left(\frac{1}{r^{\wedge} \mathrm{b}}\right) i}
$$

Trong đó $\mathrm{P}$ là tần suất hạn hán; $\mathrm{i}$ là chỉ số các trạm lân cận thứ $\mathrm{i}$; ri là khoảng cách không gian giữa 2 điểm nghiên cứu đến trạm thứ $i$; Số mũ $b$ càng cao thì mức độ ảnh hưởng của các điểm ở xa càng thấp và một số xem như không đáng kể, thông thường $b=2$ [4-5].

* Bản đồ phân vùng hạn khí tượng được thực hiện với hai mục tiêu sau:

- Phản ánh trung thực những đặc điểm và quy luật phân hóa chủ yếu về hạn hán đã được phân tích, đúc kết.

- Cung cấp thông tin cô đọng và khái quát về sự hình thành các vùng có điệu kiện hạn khí tượng khác nhau.

* Các nguyên tắc xây dựng bản đồ phân vùng hạn hán:

- Bảo đảm tính khoa học của sơ đồ phân vùng thông qua việc lựa chọn và xác định các phân hóa chủ yếu về hạn hán.

- Coi thông tin hạn được mô tả trê các bảng và phụ lục số liệu là cơ sở chủ yếu của sơ đồ phân vùng hạn.

- Tôn trọng và quán triệt ý nghĩa phổ biến về ranh giới trong sơ đồ phân vùng khí hậu, đo đó ranh giới trong sơ đồ phân vùng khô hạn là tượng trưng cho sự quá độ giữa các đơn vị khô hạn kế cận.

\section{Kết quả nghiên cứu}

\subsection{Tính toán chỉ số khô hạn $(K)$}

Sử dụng số liệu của 12 trạm KTTV trên khu vực tỉnh Bình Thuận, tính toán chỉ số khô hạn $(\mathrm{K})$ theo tháng, kết quả tính toán chỉ chỉ số khô hạn trên cơ sở số liệu mưa (tháng và năm), bốc hơi picher (tháng và năm) của các trạm khí tượng, thuỷ văn ở tỉnh Bình Thuận. 
Qua kết quả tính toán chỉ số khô hạn năm ở Bình Thuận phổ biến là $0,8-3,2$ riêng ở Phan Rí (Tuy Phong) đạt trị số cao nhất là 3,2 ; có nghĩa là lượng bốc hơi (phần chi) cao hơn gần gấp 3 lần lượng mưa (phần thu). Nơi có chỉ số khô hạn thấp hơn 0,9 là $\mathrm{Ngã} \mathrm{Ba} \mathrm{46,} \mathrm{La} \mathrm{Gi,} \mathrm{Võ}$ $\mathrm{Xu}$, Tà $\mathrm{Pao}$ và $\mathrm{La}$ Ngâu. Ở Bình Thuận, chỉ số khô hạn thấp dần từ bắc vào nam và từ vùng thấp lên vùng cao (Bảng 3 ).

Bảng 3. Kết quả chỉ số (K) năm tỉnh Bình Thuận.

\begin{tabular}{|c|c|c|c|c|c|c|c|c|c|c|c|c|}
\hline Năm & $\begin{array}{c}\text { Phan } \\
\text { Rí }\end{array}$ & $\begin{array}{c}\text { Sông } \\
\text { Lũy }\end{array}$ & $\begin{array}{c}\text { Hồng } \\
\text { Liêm }\end{array}$ & $\begin{array}{c}\text { Ma } \\
\text { Lâm }\end{array}$ & $\begin{array}{l}\text { Phan } \\
\text { Thiết }\end{array}$ & $\begin{array}{l}\text { Hàm } \\
\text { Kiệm }\end{array}$ & $\begin{array}{r}\text { Tà } \\
\text { Pao }\end{array}$ & $\begin{array}{c}\text { Ngã Ba } \\
46 \\
\end{array}$ & La Gi & Võ Xu & $\begin{array}{c}\text { La } \\
\text { Ngâu }\end{array}$ & $\begin{array}{l}\text { Phú } \\
\text { Quý }\end{array}$ \\
\hline 1978 & 4,5 & 1,4 & 2,1 & 0,5 & 0,9 & 1,3 & 0,6 & 1,2 & 0,7 & 1,1 & 0,5 & 0,0 \\
\hline 1979 & 5,9 & 1,6 & 2,6 & 1,1 & 1,1 & 1,7 & 0,6 & 0,4 & 0,9 & 1,1 & 0,5 & 1,2 \\
\hline 1980 & 2,4 & 0,7 & 2,0 & 0,6 & 0,9 & 0,7 & 0,7 & 0,6 & 0,7 & 1,3 & 0,6 & 0,8 \\
\hline 1981 & 3,2 & 1,0 & 2,6 & 0,6 & 1,1 & 1,1 & 0,7 & 0,4 & 0,8 & 1,3 & 0,7 & 0,6 \\
\hline 1982 & 4,1 & 1,1 & 2,5 & 1,2 & 1,1 & 1,2 & 0,7 & 0,5 & 0,8 & 1,3 & 1,0 & 0,0 \\
\hline 1983 & 3,8 & 1,2 & 2,9 & 1,7 & 1,3 & 1,2 & 0,7 & 0,8 & 1,0 & 0,8 & 1,2 & 0,7 \\
\hline 1984 & 3,4 & 1,0 & 2,5 & 1,8 & 1,1 & 1,1 & 0,7 & 1,2 & 0,7 & 0,5 & 1,1 & 0,9 \\
\hline 1985 & 6,7 & 2,6 & 3,6 & 1,6 & 1,7 & 2,6 & 0,9 & 1,2 & 0,9 & 1,2 & 1,0 & 0,6 \\
\hline 1986 & 4,2 & 1,2 & 2,0 & 1,5 & 1,0 & 1,3 & 0,7 & 1,4 & 0,7 & 0,5 & 0,9 & 0,7 \\
\hline 1987 & 4,4 & 1,6 & 2,8 & 0,9 & 1,5 & 1,6 & 0,8 & 1,5 & 1,0 & 0,7 & 0,6 & 0,8 \\
\hline 1988 & 4,9 & 2,0 & 2,0 & 0,9 & 1,1 & 2,0 & 0,8 & 0,4 & 1,0 & 0,9 & 0,9 & 1,4 \\
\hline 1989 & 3,1 & 1,2 & 2,7 & 1,3 & 1,4 & 1,3 & 0,5 & 0,3 & 0,8 & 0,8 & 0,6 & 1,6 \\
\hline 1990 & 3,4 & 2,0 & 2,7 & 2,0 & 1,6 & 1,9 & 0,7 & 0,3 & 0,9 & 1,2 & 0,7 & 1,1 \\
\hline 1991 & 4,7 & 2,3 & 2,2 & 1,7 & 1,4 & 2,2 & 0,7 & 0,4 & 0,9 & 1,3 & 0,8 & 1,3 \\
\hline 1992 & 3,8 & 1,8 & 3,1 & 2,9 & 1,8 & 1,8 & 0,9 & 1,2 & 1,0 & 0,7 & 0,7 & 1,5 \\
\hline 1993 & 3,5 & 1,8 & 2,9 & 1,4 & 1,7 & 1,7 & 1,0 & 0,9 & 0,7 & 0,7 & 0,8 & 1,9 \\
\hline 1994 & 2,0 & 0,8 & 2,0 & 1,1 & 1,0 & 0,8 & 0,7 & 0,8 & 0,8 & 0,6 & 0,6 & 1,2 \\
\hline 1995 & 3,1 & 1,8 & 2,6 & 1,7 & 1,4 & 1,7 & 1,0 & 0,9 & 0,9 & 0,9 & 0,8 & 1,3 \\
\hline 1996 & 2,0 & 0,8 & 1,8 & 1,1 & 0,9 & 0,9 & 0,7 & 0,7 & 0,9 & 0,7 & 0,7 & 0,6 \\
\hline 1997 & 2,9 & 1,2 & 3,3 & 1,4 & 1,6 & 1,3 & 0,7 & 0,9 & 0,8 & 0,6 & 0,8 & 1,3 \\
\hline 1998 & 2,1 & 0,9 & 2,6 & 1,1 & 1,1 & 0,9 & 0,7 & 1,0 & 1,2 & 0,7 & 0,7 & 0,7 \\
\hline 1999 & 2,0 & 0,7 & 1,4 & 1,6 & 0,6 & 0,8 & 0,6 & 0,7 & 0,8 & 0,6 & 0,6 & 0,8 \\
\hline 2000 & 2,3 & 0,9 & 1,6 & 1,3 & 0,8 & 1,0 & 0,6 & 0,7 & 0,8 & 0,6 & 0,6 & 0,8 \\
\hline 2001 & 2,9 & 1,3 & 2,5 & 1,9 & 1,2 & 1,4 & 0,6 & 0,8 & 0,8 & 0,6 & 0,6 & 0,9 \\
\hline 2002 & 3,4 & 1,4 & 2,4 & 1,5 & 1,2 & 1,5 & 0,8 & 1,1 & 0,9 & 0,9 & 0,8 & 1,2 \\
\hline 2003 & 2,7 & 1,2 & 2,2 & 1,1 & 1,1 & 1,3 & 0,7 & 1,0 & 0,7 & 0,7 & 0,8 & 0,6 \\
\hline 2004 & 3,3 & 1,3 & 3,1 & 2,5 & 1,3 & 1,4 & 1,0 & 1,2 & 1,5 & 0,9 & 1,0 & 1,5 \\
\hline 2005 & 3,1 & 1,3 & 2,3 & 2,0 & 1,1 & 1,4 & 0,7 & 1,0 & 1,1 & 0,7 & 0,7 & 1,4 \\
\hline 2006 & 2,8 & 1,2 & 1,9 & 1,3 & 1,0 & 1,2 & 0,6 & 0,7 & 0,9 & 0,5 & 0,6 & 1,2 \\
\hline 2007 & 2,4 & 1,2 & 1,9 & 1,3 & 1,1 & 1,3 & 0,6 & 0,6 & 0,6 & 0,6 & 0,6 & 1,0 \\
\hline 2008 & 2,3 & 1,1 & 2,1 & 1,7 & 1,2 & 1,1 & 0,8 & 0,7 & 0,7 & 0,6 & 0,6 & 1,1 \\
\hline 2009 & 3,3 & 2,3 & 2,4 & 1,7 & 1,5 & 2,2 & 0,6 & 0,8 & 1,0 & 0,7 & 0,6 & 1,2 \\
\hline
\end{tabular}




\begin{tabular}{cccccccccccccc}
\hline \multirow{2}{*}{ Năm } & $\begin{array}{c}\text { Phan } \\
\text { Rí }\end{array}$ & $\begin{array}{c}\text { Sông } \\
\text { Lũy }\end{array}$ & $\begin{array}{c}\text { Hồng } \\
\text { Liêm }\end{array}$ & $\begin{array}{c}\text { Ma } \\
\text { Lâm }\end{array}$ & $\begin{array}{c}\text { Phan } \\
\text { Thiết }\end{array}$ & $\begin{array}{c}\text { Hàm } \\
\text { Kiệm }\end{array}$ & $\begin{array}{c}\text { Tà } \\
\text { Pao }\end{array}$ & $\begin{array}{c}\text { Ngã Ba } \\
\mathbf{4 6}\end{array}$ & La Gi Võ Xu & \multicolumn{3}{c}{ La } & Phúu \\
Quý \\
\hline 2010 & 3,6 & 2,0 & 2,6 & 2,1 & 1,5 & 2,0 & 1,0 & 0,9 & 1,1 & 1,2 & 1,1 & 0,7 \\
2011 & 2,4 & 1,6 & 2,1 & 1,7 & 1,2 & 1,6 & 0,6 & 1,0 & 0,8 & 0,7 & 0,7 & 1,9 \\
2012 & 2,3 & 1,2 & 2,0 & 1,4 & 1,2 & 1,2 & 0,6 & 0,9 & 0,8 & 0,6 & 0,7 & 1,2 \\
2013 & 2,3 & 1,4 & 3,1 & 2,0 & 1,7 & 1,4 & 0,7 & 1,0 & 1,1 & 0,9 & 0,8 & 1,0 \\
2014 & 4,1 & 1,5 & 2,5 & 2,0 & 1,4 & 1,4 & 1,0 & 0,9 & 0,9 & 0,9 & 0,9 & 1,3 \\
2015 & 4,3 & 1,8 & 3,2 & 2,1 & 1,8 & 1,7 & 1,2 & 1,2 & 1,2 & 1,0 & 1,1 & 1,0 \\
2016 & 1,8 & 1,4 & 2,1 & 1,5 & 1,2 & 1,4 & 0,8 & 0,8 & 0,7 & 1,0 & 0,8 & 0,8 \\
2017 & 1,4 & 0,9 & 2,8 & 1,6 & 1,3 & 1,0 & 0,7 & 0,7 & 0,7 & 0,7 & 0,6 & 0,5 \\
2018 & 2,0 & 1,3 & 2,6 & 0,8 & 1,2 & 1,4 & 0,8 & 0,4 & 0,8 & 1,6 & 0,7 & 0,9 \\
2019 & 2,6 & 2,0 & 3,0 & 0,6 & 1,6 & 2,0 & 0,8 & 0,3 & 0,6 & 0,8 & 0,7 & 1,2 \\
2020 & 2,1 & 0,9 & 2,9 & 0,9 & 1,5 & 0,9 & 0,8 & 0,5 & 0,7 & 0,8 & 0,8 & 0,7 \\
Trung bình & 3,2 & 1,4 & 2,5 & 1,5 & 1,3 & 1,4 & 0,8 & 0,8 & 0,9 & 0,9 & 0,8 & 1,0 \\
\hline
\end{tabular}

\subsection{Chỉ số khô hạn(K) tháng, mùa và tần suất xuất hiện}

* Chỉ số khô hạn $\mathrm{K}$ trên các khu vực

Kết quả tính toán chỉ số (K) theo tháng cho thấy chỉ số khô hạn xảy ra ở tỉnh Bình Thuận hầu hết vào các tháng đầu năm và cuối năm (trong thời gian từ tháng 11 năm trước đến hết tháng 4 năm sau), chỉ số khô hạn trên toàn tỉnh phổ biến từ hơi khô đến rất khô $(\mathrm{K}>1,3)$; từ tháng 5 đến tháng 10 các khu vực trong tỉnh chủ yếu ẩm ướt đến hơi khô ( $\mathrm{K}$ từ 0,3 đến 1,6$)$.

Đối với khu vực phía Bắc và Trung tâm của tỉnh (trạm KT Phan Rí, TV Sông Lũy, KT Phan Thiết,...) chỉ số khô đến rất khô thường kéo dài hơn so với phía Nam và Tây nam tỉnh. Riêng Tuy Phong, Bắc Bình hạn kéo dài gần như quanh năm như trạm Phan Rí (12 tháng), Hồng Liêm (11 tháng). Đối với khu vực Tây Nam của tỉnh (trạm KT La Gi, TV Tà Pao, Võ $\mathrm{Xu}, .$. ) chỉ số khô đến rất khô thường kéo dài 6 tháng (từ tháng 11 năm trước đến tháng 4 năm sau).

* Các mùa khô, ẩm trên toàn tỉnh

Mùa khô (6 tháng):Từ tháng 12 năm trước đến tháng 4 năm sau chỉ số $\mathrm{K}$ phổ biến từ khô đến rất khô $(\mathrm{K}>2,8)$; riêng tháng 11 là tháng chuyển tiếp giữa mùa mưa và mùa mưa chỉ số $\mathrm{K}$ phổ biến từ 1,3 đến 3,6 . Chỉ số khô hạn ở khu vực phía Đông, Đông Bắc và Trung tâm tỉnh thường cao hơn so với các khu vực khác trong tỉnh, nhiều nơi gấp hơn 3 lần.

Mùa mưa: Từ tháng 5 năm đến tháng 10 chỉ số $\mathrm{K}$ phổ biến từ rất ẩm đến hơi khô $(\mathrm{K}$ từ 0,3 đến 1,6$)$. Đối với khu vực Tây nam của tỉnh mùa mưa các tháng ẩm đến rất ẩm (không cần tưới) dài hơn so với phía Bắc và Trung tâm tỉnh, thể hiện khu vực này hạn ít khắc nhiệt hơn, chủ yếu xảy ra hạn cục bộ ở một số nơi trong khu vực (Bảng 4).

Bảng 4. Kết quả chỉ số khô hạn $(K)$ tháng, năm tỉnh Bình Thuận.

\begin{tabular}{llllllllllllll}
\hline Trạm & $\mathbf{1}$ & $\mathbf{2}$ & $\mathbf{3}$ & $\mathbf{4}$ & $\mathbf{5}$ & $\mathbf{6}$ & $\mathbf{7}$ & $\mathbf{8}$ & $\mathbf{9}$ & $\mathbf{1 0}$ & $\mathbf{1 1}$ & $\mathbf{1 2}$ & Năm \\
\hline Phan Rí & 71,1 & 970,9 & 33,4 & 15,3 & 1,6 & 1,4 & 1,4 & 1,3 & 1,0 & 1,2 & 3,6 & 12,8 & 3,2 \\
Sông Lũy & 39,9 & 380,1 & 13,9 & 7,3 & 0,9 & 0,8 & 0,7 & 0,8 & 0,5 & 0,5 & 1,4 & 6,8 & 1,4 \\
Hồng Liêm & 59,5 & 883,3 & 47,5 & 9,8 & 1,6 & 1,3 & 1,1 & 1,1 & 0,9 & 1,2 & 3,3 & 11,2 & 2,5 \\
Ma Lâm & 37,2 & 308,3 & 21,8 & 6,2 & 1,0 & 0,6 & 0,6 & 0,5 & 0,5 & 0,7 & 1,6 & 8,5 & 1,5 \\
Phan Thiết & 29,9 & 377,8 & 23,7 & 4,7 & 0,8 & 0,7 & 0,6 & 0,6 & 0,5 & 0,6 & 1,6 & 5,8 & 1,3 \\
\hline
\end{tabular}




\begin{tabular}{lcccccccccccccc}
\hline Trạm & $\mathbf{1}$ & $\mathbf{2}$ & $\mathbf{3}$ & $\mathbf{4}$ & $\mathbf{5}$ & $\mathbf{6}$ & $\mathbf{7}$ & $\mathbf{8}$ & $\mathbf{9}$ & $\mathbf{1 0}$ & $\mathbf{1 1}$ & $\mathbf{1 2}$ & Năm \\
\hline Hàm Kiệm & 36,8 & 309,3 & 13,4 & 7,0 & 0,9 & 0,8 & 0,7 & 0,8 & 0,5 & 0,5 & 1,4 & 6,5 & 1,4 \\
Tà Pao & 24,0 & 64,4 & 14,9 & 2,9 & 0,6 & 0,4 & 0,3 & 0,3 & 0,3 & 0,5 & 1,3 & 5,8 & 0,8 \\
Ngã Ba 46 & 33,6 & 191,2 & 20,8 & 2,8 & 0,5 & 0,3 & 0,3 & 0,3 & 0,3 & 0,4 & 1,3 & 6,2 & 0,8 \\
La Gi & 65,8 & 478,9 & 20,7 & 4,1 & 0,7 & 0,4 & 0,3 & 0,3 & 0,3 & 0,4 & 2,0 & 5,1 & 0,9 & 0,9 \\
Võ Xu & 31,8 & 37,1 & 11,3 & 3,0 & 0,7 & 0,4 & 0,3 & 0,3 & 0,3 & 0,5 & 1,3 & 5,6 & 0,9 \\
La Ngâu & 36,3 & 47,3 & 11,9 & 2,8 & 0,7 & 0,4 & 0,3 & 0,3 & 0,3 & 0,5 & 1,4 & 7,5 & 0,8 \\
Phú Quý & 9,7 & 24,2 & 9,3 & 2,8 & 0,9 & 0,7 & 0,8 & 0,9 & 0,5 & 0,4 & 0,6 & 1,4 & 1,1 \\
\hline
\end{tabular}

Điều đáng lưu ý là, trong những trường hợp lượng bốc hơi tháng quá cao và lượng mưa tháng quá thấp, chỉ số $\mathrm{K}$ cao hơn 100 thì chấp nhận giá trị tối đa là 100 (có nghĩa là phần chi cao hơn phần thu 100 lần). Thực tế cho thấy, với giá trị tối đa có thể hình dung được mức độ khô hạn ở các vùng trong tỉnh.

* Tần suất khô hạn trên các khu vực tỉnh

Khu vực phía bắc và trung tâm tỉnh: Tần xuất xuất hiện chỉ số khô hạn từ khô đến rất khô chiếm tỷ lẹ̣ 79-100\% (Bảng 5). Khu vực phía nam tỉnh:Tần xuất xuất hiện chỉ số khô hạn từ hơi khô đến khô chiếm tỷ lệ 9-23\%. Riêng huyện đảo Phú Quý chỉ số khổ hạn xảy ra từ tháng 12 năm trước đến hết tháng 4 năm sau. Tần xuất xuất hiện chỉ số khô hạn hơi khô chiếm tỷ lệ $48,8 \%$. Mùa mùa khô trên địa bàn tỉnh Bình Thuận đều có tần suất xảy ra khô hạn từ khô đến rất khô chiếm tỷ lệ $83-100 \%$; hơi khô đến ẩm chiếm tỉ lệ $0-17 \%$. Ngược lại mùa mưa tần suất khô hạn gần như ẩm đến hơi khô.

Bảng 5. Chỉ số khô hạn mùa, năm và tần suất xuất hiện tại các trạm (Đơn vị: \%).

\begin{tabular}{|c|c|c|c|c|c|c|c|c|}
\hline \multicolumn{9}{|c|}{ Mức độ hạn } \\
\hline Trạm & $\begin{array}{l}\text { Rất } \\
\text { khô }\end{array}$ & Khô & $\begin{array}{l}\text { Hơi } \\
\text { khô }\end{array}$ & Ầm & Rất ẩm & K(MK) & K(TBNN) & $\begin{array}{l}\text { Mức độ hạn } \\
\text { năm }\end{array}$ \\
\hline Phan Rí & 23,3 & 69,8 & 7,0 & 0,0 & 0,0 & 10,3 & 3,2 & Khô \\
\hline Sông Lũy & 0,0 & 11,6 & 67,4 & 20,9 & 0,0 & 4,1 & 1,4 & Hơi khô \\
\hline Hồng Liêm & 0,0 & 83,7 & 16,3 & 0,0 & 0,0 & 7,2 & 2,5 & Khô \\
\hline Ma Lâm & 0,0 & 14,0 & 67,4 & 18,6 & 0,0 & 4,5 & 1,5 & Hơi khô \\
\hline Phan Thiết & 0,0 & 0,0 & 83,7 & 16,3 & 0,0 & 3,6 & 1,3 & Hơi khô \\
\hline Hàm Kiệm & 0,0 & 11,6 & 69,8 & 18,6 & 0,0 & 14,6 & 1,4 & Hơi khô \\
\hline Tà Pao & 0,0 & 0,0 & 9,3 & 90,7 & 0,0 & 2,6 & 0,8 & Ẩm \\
\hline Ngã Ba 46 & 0,0 & 0,0 & 23,3 & 55,8 & 20,9 & 2,5 & 0,8 & Ầm \\
\hline La Gi & 0,0 & 0,0 & 18,6 & 81,4 & 0,0 & 3,2 & 0,9 & Âm \\
\hline Võ Xu & 0,0 & 0,0 & 23,3 & 74,4 & 2,3 & 2,9 & 0,9 & Âm \\
\hline La Ngâu & 0,0 & 0,0 & 14,0 & 83,7 & 2,3 & 2,7 & 0,8 & Ấm \\
\hline Phú Quý & 0,0 & 0,0 & 48,8 & 46,5 & 4,7 & 2,2 & 1,0 & Hơi khô \\
\hline
\end{tabular}

\subsection{Bản đồ phân vùng khô hạn}

Trong quá trình phân tích tính chất, mức độ và phân vùng hạn các nhà nghiên cứu lựa chọn chỉ số khô hạn tháng và năm. Hai chỉ số này vừa có khả năng phản ánh cán cân thu chi về nước trong các tháng cũng như trong cả năm vừa là cơ sở của việc phân định các mùa khô/ ẩm trên từng khu vực và trên phạm vi toàn tỉnh. Phân hóa về hạn gắn liền với phân hóa về mưa, đặc biệt về mùa mưa [17]. 
Trên mỗi vùng khô hạn hình thành nhiều tiểu vùng có cấp độ hạn khác nhau [18]. Tuy vậy cấp độ hạn nặng xảy ra hầu khắp trên các tiểu vùng thuộc khu vực tỉnh. Trên nền chung là khí hậu nhiệt đới gió mùa nhưng do sự phân hóa và nâng lên của địa hình, khí hậu Bình Thuận đã phân hóa thành những vùng và tiểu vùng khô hạn với một số khác biệt so với các khu vực khác ở Việt Nam (Hình 3).
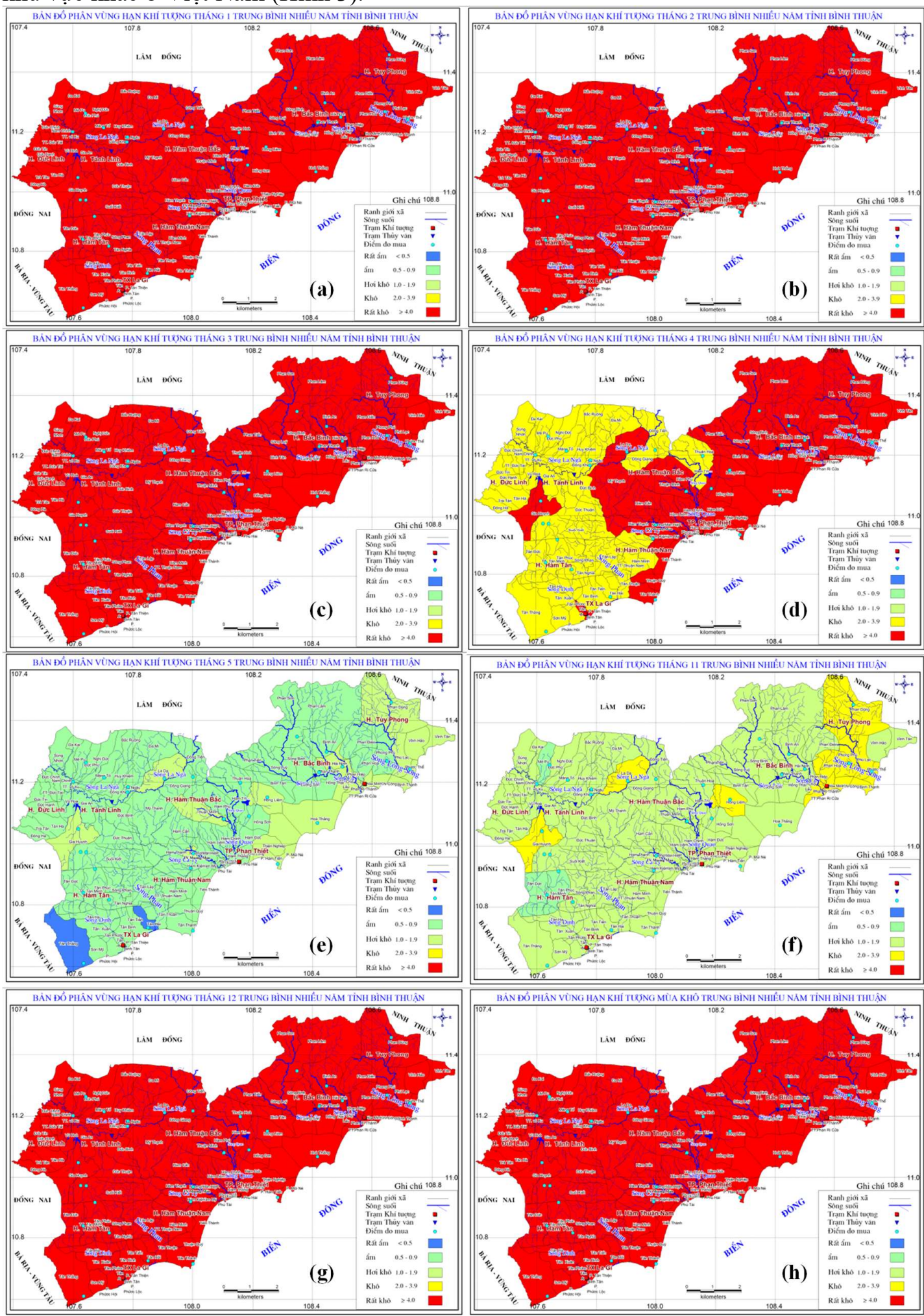

Hình 3. Bản đồ chỉ số hạn $\mathrm{K}$ tháng, mùa khô, năm. 
Như vậy chỉ số đánh giá mức độ khô hạn xảy ra mùa khô từ tháng 11 năm trước đến tháng 4 năm sau là rất phù hợp với tình hình mưa tại tỉnh Bình Thuận, tổng lượng mưa toàn mùa khô các nơi phổ biến từ 125-490 mm, chiếm khoảng 13-23\% ở mức rất thấp so với tổng lượng mưa năm. Trong khi đó lượng mưa năm khu vực bắc và ven biển chỉ đạt $700-1.260$ $\mathrm{mm} / \mathrm{năm}$. Khu vực phía nam lượng mưa năm đạt từ 1.600-2.200 mm/năm.

\section{Kết luận}

Trên cơ sở bộ số liệu KTTV (thời gian và không gian), kết hợp với số liệu khảo sát khí hậu sử dụng các công thức tính toán các chỉ số hạn $(\mathrm{K})$. Chỉ số hạn đã thể hiện được các vùng hạn khác nhau trên địa bản toàn tỉnh về cấp độ hạn, thời gian hạn, thời gian kết thúc đợt hạn, thời gian đợt hạn kéo dài,... Kết quả tính toán, đánh giá chỉ số hạn sát với những năm hạn thực tế đã xảy ra trên địa bàn tỉnh Bình Thuận. Các chỉ số khô hạn tháng, mùa, năm đều trùng với thời kỳ ít mưa trong năm. Việc phân tích lựa chọn, ứng dụng chỉ số khô hạn $(\mathrm{K})$ làm công cụ tính toán khô hạn tương đối phù hợp so với các chỉ số khô hạn khác đã nêu ở trên (SPI, $\left.\mathrm{D}, \mathrm{TC}, \mathrm{K}_{\mathrm{hạn}}, \ldots\right)$. Riêng các chỉ số SPDI, SWSI không khả quan vì số liệu nước ngầm, độ ẩm đất,... .rất ít hoặc không có. Xác định tần suất xuất hiện khô hạn xảy ra trên địa bàn tỉnh theo tháng, mùa (theo chỉ số $\mathrm{K}$ ) làm cơ sở cho việc xây dựng bản đồ phân vùng khô hạn tháng, mùa, năm phục vụ cho công tác dự báo và giám sát hạn hán khu vực tỉnh Bình Thuận.

Như đã phân tích tình hình hạn hán trong những năm gần đây của cả nước nói chung và tỉnh Bình Thuận nói riêng đã cho thấy hạn hán, biến đổi khí hậu đã làm ảnh hưởng rất lớn đến phát triển kinh tế cũng như đời sống của người dân $[11,14,15]$. Bình Thuận được xem là tỉnh khô hạn nhất cả nước chỉ sau Ninh Thuận, lượng mưa trung bình năm thấp, khả năng cung cấp nguồn nước trong mùa khô gặp rất nhiều khó khăn cho sản xuất; đặc biệt hạn thường gây gắt nhất vào những thời kỳ El- Nino mạnh [19-20]. Phân bố mưa theo không gian và thời gian hết sức bất lợi cho cây trồng; đặc biệt là khu vực Tuy Phong, Bắc Bình, Hàm Thuận Bắc. Mùa khô hạn chiếm từ $7-9$ tháng trong năm, trong đó từ tháng 1 đến tháng 4 hàng năm là khô hạn nặng. Cuối năm 2019 đầu năm 2020, diễn biến hạn phức tạp, ảnh hưởng đến đời sống kinh tế xã hội, tỉnh Bình Thuận phải công bố mức độ hạn cấp 2.

Việc xây dựng bản đồ khô hạn hàng tháng, mùa, năm khu vực tỉnh Bình Thuận trên dựa trên chỉ số $(\mathrm{K})$ chưa thể hiện hết tác động của hạn hán ở các vùng. Để xây dựng bản đồ sát với tình hình diễn biến hạn tại các vùng, tiểu vùng cần xem xét một cách tổng hợp các loại hạn: hạn khí tượng, hạn nông nghiệp và hạn thủy văn. Từ đó có thể sử dụng để đánh giá và giám sát hạn hán trên phạm vi toàn tỉnh. Bản đồ phân vùng hạn hán là cơ sở có thể áp dụng vào trong công tác dự báo, cảnh báo hạn sớm hiệu quả trên địa bàn tỉnh.

Đóng góp của tác giả: Xây dựng ý tưởng nghiên cứu: N.H.T., T.V.H., T.T.N.; Lựa chọn phương pháp nghiên cứu: N.H.T., T.V.H., T.T.N.; Thu thập, phân tích, tính toán xử lý số liệu: N.H.T., T.V.H., T.T.N.; Viết bản thảo bài báo: N.H.T., T.V.H., T.T.N.; Chỉnh sửa bài báo: N.H.T.

Lời cảm ơn: Tác giả chân thành trọng cám ơn tới Đài Khí tượng thủy văn tỉnh Bình Thuận, Ban chỉ huy phòng chống thiên tai, tìm kiếm cứu nạn tỉnh Bình Thuận đã phối hợp để hoàn thành đề tài và có bài báo này. Trân trọng cám ơn Ban biên tập Tạp chí Khí tượng Thủy văn, Tổng cục Khí tượng Thủy văn.

Lò̀i cam đoan: Tác giả cam đoan bài báo này là công trình nghiên cứu tác giả, chưa được công bố ở đâu, không sao chép từ những nghiên cứu trước đây; không có sự tranh chấp lợi ích.

\section{Tài liệu tham khảo}

1. Hiệu, T.N. Phân bố hạn hán và tác động của nó ở Việt Nam, 1995.

2. Học, X.Đ. Nghiên cứu các giải pháp giảm nhẹ thiên tai hạn hán ở các tỉnh Duyên hải miền Trung từ Hà Tĩnh đến Bình Thuận, 2001. 
3. Ngữ, N.Đ.; Hiệu, N.T. Tìm hiểu về hạn hán và hoang mạc hoá. Nhà xuất bản Khoa học và Kĩ thuật, Hà Nội, 2002.

4. Kim, N.Q. và cs. Nghiên cứu dự báo hạn hán vùng Nam Trung bộ và Tây Nguyên và xây dựng các giải pháp phòng chống, 2005.

5. Thục, T. Xây dựng bản đồ hạn hán và mức độ thiếu nước sinh hoạt ở Nam Trung Bộ và Tây Nguyên. Đề án cấp Bộ - Viện Khoa học KTTV và Môi trường, 2008.

6. Sâm, L.; Vượng,N.Đ. Nghiên cứu đánh giá tình hình hạn hán, thiếu nước trong mùa khô, xây dựng phương án cảnh báo và bản đồ phân vùng hạn hán tỉnh Ninh Thuận. Báo cáo tổng kết đề tài cấp tỉnh, 2008.

7. Trường, N.H. Phân vùng khô hạn một số kiến nghị bảo vệ tài nguyên nước mặt phục vụ cho sản xuất nông nghiệp và phát triển kinh tế xã hội tỉnh Ninh Thuận, 2007.

8. Thắng, N.V. Nghiên cứu và xây dựng công nghệ dự báo và cảnh báo sớm hạn hán ở Việt Nam, Đề tài NCKH, Viện KTTV, Bộ Tài nguyên và Môi trường, 2007.

9. Thắng, N.V.; Khiêm, M.V.; Mậu, N.Đ.; Trí, T.Đ. Nghiên cứu xác định chỉ tiêu hạn hán cho vùng Nam trung bộ. Tạp chi Khi tương Thủy văn 2014, 639, 49-55.

10. Hoa, N.N.; An, N.L; Trí, Đ.Q.; Đạt, T.T; Mai, Đ.T.; Trường, Đ.Đ. Nghiên cứu phương pháp dự báo hạn khí tượng thủy văn áp dụng cho khu vực tỉnh Đăk Lăk, Tây Nguyên. Tạp chi Khi tượng Thủy văn 2019, 699, 30-41.

11. Thành, N.N.; Thái, T.H.; Dũng, B.Q. Nghiên cứu xây dựng bản đồ phân vùng hạn hán lưu vực sông Ba trong bối cảnh biến đổi khí hậu. Tạp chí Khí tượng Thủy văn 2019, 704, 20-27.

12. Prathumchai, K.; Honda,K.; Nualchawee, K. Drought riske valuation using remote sensing and GIS: A case study in Buri province. Proceeding of the $22^{\text {nd }}$ Asian Conference on Remote Sensing, 5 - 9 November 2001, Singapore, 2001, pp. 6.

13. Thông, M.T; Hiền, N.T. Nguyên nhân và giải pháp phòng ngừa, ngăn ngừa quá trình hoang mạc hóa ở Nam Trung Bộ Việt Nam (Ninh Thuận - Bình Thuận). Mã số KH07-01- Viện địa lý, 1999.

14. Hiệu, N.T.; Thắng, N.V.; Hương, P.T.T. Tác động của biến đổi khí hậu đến hạn hán trên các vùng khí hậu ở Việt Nam. Tạp chí Khí tượng Thủy văn 2010, 598, 21-25.

15. World Meteorological Organization: Drought monitoring and early warning: Concepts, progress and future challenges. Weather and climate information for sustainable agricultural development. WMO-No.1006, 2006.

16. Hương, N.T. Đặc điểm Khí tượng Thủy văn Bình Thuận năm, 2014.

17. Hiệu, N.T; Hương, P.T.T; Ngọc, L.T.B. Đặc điểm hạn và phân vùng hạn ở Việt Nam. Báo cáo hội thảo khoa học Viện KTTV lần thứ 8, 2003.

18. Tri, D.Q.; Truong, D.D.; Dat, T.T. Application of Meteorological and Hydrological drought indices to establish drought classification maps of the Ba river basin in Viet Nam. Hydrology 2019, 6, 49.

19. Thuận, H.T; Đại, H.V. Đánh giá nhu cầu dùng nước của tỉnh Bình Thuận dưới tác động của biến đổi khí hậu. Tạp chí Khi tuợng Thủy văn 2014, 638, 18-22.

20. Ngữ, $\mathrm{N} Đ$. ENSO và hạn hán ở các tỉnh ven biển miền Trung và Tây Nguyên. Tạp chi Khi tượng thủy văn 2005, 530(2), 1-15.

\section{Research on droughts based on the drought index (K) on Binh Thuan province}

Nguyen Hong Truong ${ }^{*}$, Tran Van Hung1, Tu Thi Nam²

${ }^{1}$ Sougth Central Regional Hydro-Meteorological Station; truongmeteo@gmail.com; tranhungdubao@gmail.com

${ }^{2}$ HCM Natural Resources and Environment University; ttnam@hcmunre.edu.vn 
Abstract: On Binh Thuan province, drought, lacking of water shortages, water resources are increasingly scarce. To ensure enough water for socio-economic development, the management, prevention-term problems that need attention. Nowadays, many of defferent calculating indexes have been applies many countries and Viet Nam. This paper has presented dronght index ( $\mathrm{K}$ index of water balance) assessing drought, lack of water and construction of drought map on Binh Thuan province gave an overview about the term and limited ability to occur on river basin and this is also the basis for establishing reference in the evaluation system, monitoring and drought warning.

Keywords: Drought Index (K); Droughty frequency; Binh Thuan Province. 